\title{
AUDIODESCRIÇÃO E EDUCAÇÃO AMBIENTAL: DIÁLOGOS POLÍTICOS E PEDAGÓGICOS ${ }^{1}$
}

\author{
Jorge Amaro de Souza Borges ${ }^{2}$ \\ Thiele Araujo Pereira ${ }^{3}$
}

\begin{abstract}
Resumo: A sociedade moderna passa por muitas transformações, as quais afetam diretamente nosso modo de ver e agir no mundo. Ao longo da história, extermínio, exclusão, segregação, integração foram conceitos que fazem parte da vida das pessoas com deficiência. O presente trabalho busca identificar a construção das políticas públicas de acessibilidade e inclusão, suas transformações conceituais e como a audiodescrição se estabelece neste contexto, ou seja, como se afirma teórica e politicamente. Como utilizar a audiodescrição como uma ferramenta pedagógica nos processos de educação ambiental? A ideia de acessibilidade e sustentabilidade é trabalhada para pensar novas concepções pedagógicas que conectem saberes individuais e coletivos a partir da compreensão de que o meio ambiente é um direito de todos, inclusive das pessoas com deficiência. São apresentadas as principais normas no âmbito do Brasil e como as mesmas são influenciadas por documentos internacionais e quais são os atores envolvidos nestes processos. Por fim, há uma tentativa de conectar estas questões como dimensões de uma política pública de educação para todas as pessoas, oferecendo sugestões de acessibilidade a projetos e programas de educação ambiental no âmbito federal.
\end{abstract}

Palavras-chave: Acessibilidade; Sustentabilidade; Direitos Humanos; Cidadania; Políticas Públicas.

\section{AUDIO DESCRIPTION AND ENVIRONMENTAL EDUCATION: POLITICAL AND PEDAGOGICAL DIALOGUES}

\begin{abstract}
Modern society undergoes many transformations, which directly affect our way of seeing and acting in the world. Throughout history, extermination, exclusion, segregation, integration were concepts that are part of the lives of people with disabilities. The present work seeks to identify the construction of public policies of accessibility and inclusion, its conceptual transformations and how audiodescription is established in this context, that is, as it is theoretically and politically affirmed. How to use audiodescription as a pedagogical tool in environmental education processes? The idea of accessibility and sustainability is worked to think new pedagogical conceptions that connect individual and collective knowledge from the understanding that the environment is a right of everyone, including people with disabilities. The main norms are presented in Brazil and how they are influenced by international documents and which are the actors involved in these processes. Finally, there is an attempt to connect these issues as dimensions of a public education policy for all people, offering suggestions of accessibility to projects and programs of environmental education at the federal level.
\end{abstract}

Keywords: Accessibility; Sustainability; Human rights; Citizenship; Public policy.

\section{Reflexões Iniciais}

$\mathrm{O}$ que nos estimula escrever e estudar determinado assunto? O que faz alguns temas terem maior ou menor destaque em nossas vidas? Conforme Galeano (2012) além de átomos, somos formados por histórias, e estas, nascem todos os dias, nos guiam, emocionam e buscam dar sentido a nossas práticas. Este trabalho tem em sua composição, primeiramente, os estudos sobre audiodescrição desenvolvidos no âmbito acadêmico, mas também, carrega junto de si,

\footnotetext{
${ }^{1}$ Uma versão deste texto foi publicada nos anais XI Reunião Científica da Região Sul - ANPED Sul, realizada de 24 a 27 de julho de 2016, na Universidade Federal do Paraná, em Curitiba/PR.

2 Doutorado em Programa de Pós-Graduação em Políticas Públicas pela Universidade Federal do Rio Grande do Sul, Brasil. DIRETOR PRESIDENTE do GRUPO TRANSDISCIPLINAR DE ESTUDOS AMBIENTAIS MARICÁ. Desenvolve atividades na Fundação de Articulação e Des de Políticas Públicas para PcD e PcAH no RGS, Centro Abrigado Zona Norte (CAZON), Porto Alegre - RS.

${ }^{3}$ Graduação em Letras - Espanhol pela Universidade Federal de Pelotas, em 2014. Coord. do Polo de Educação a Distância (UAB) da Prefeitura Municipal de Mostardas, Brasil.
} 
crenças pessoais de lutas coletivas. Traz assim, questões de dimensões que extrapolam o ambiente acadêmico.

A sociedade moderna passa por muitas transformações, as quais afetam diretamente nosso modo de ver e agir no mundo. Nesta perspectiva, ao longo da história, extermínio, exclusão, segregação, integração foram conceitos que fazem parte da vida das pessoas com deficiência. Para Sassaki:

A razão disto reside no fato de que a cada época são utilizados termos cujo significado seja compatível com os valores vigentes em cada sociedade enquanto esta evoluiu em seu relacionamento com as pessoas que possuem este ou aquele tipo de deficiência $(2003$, s.p.)

Com o advento da Convenção da Organização das Nações Unidas sobre os Direitos da Pessoa com Deficiência (CDPD), há uma guinada na direção dos direitos humanos e do reconhecimento destas pessoas como sujeitos de direitos a partir das ideias de protagonismo, acessibilidade e igualdade de oportunidades. Para Louis Henkin [19-]3, os direitos humanos constituem um termo de uso comum, mas não categoricamente definido, sendo desta forma, direitos concebidos de forma a incluir aquelas reivindicações morais e políticas que, no consenso contemporâneo todo ser humano tem ou deve ter perante sua sociedade ou governo, reivindicações estas reconhecidas como de direito e não apenas por amor, graça ou caridade.

É nesta dimensão, que, termos como inválidos, incapacitados, defeituosos, excepcionais, pessoas deficientes, pessoas portadoras de deficiência, pessoas com necessidades especiais, portadores de necessidades especiais, pessoas especiais, portadores de direitos especiais transitaram nas diferentes épocas e espaços temporais, construindo e ressignificando a ideia de corpo, capacidade e incapacidade, até chegarmos a terminologia atual - pessoa com deficiência, que de acordo com a Convenção da ONU (BRASIL, 2007) são:

Aquelas que têm impedimentos de longo prazo de natureza física, mental, intelectual ou sensorial, os quais, em interação com diversas barreiras, podem obstruir sua participação plena e efetiva na sociedade em igualdades de condições com as demais pessoas. (BRASIL, 2007)

Nos últimos anos, com esta nova conceituação, podemos evidenciar a ascensão de políticas públicas nas áreas da educação, saúde, trabalho e assistência social cujo teor tem garantido ampliação da participação das pessoas com deficiência nos mais diferentes espaços sociais, de certa forma, estimulados por programas governamentais como a Agenda Social ${ }^{4}$ e o

\footnotetext{
${ }^{4}$ A Agenda Social de Inclusão das Pessoas com Deficiência, como um primeiro grande esforço governamental para impulsionar a inclusão das pessoas com deficiência e a promoção da acessibilidade em nível nacional. As ações da Agenda Social estavam distribuídas nas áreas de Acessibilidade (Escola Acessível, Livro Acessível, Transporte
} 
Plano Viver sem Limite $^{5}$ que priorizaram estas questões tensionados pelo crescimento, tanto em quantidade como qualidade do referido protagonismo.

$\mathrm{Na}$ atualidade, esporte, cultura e turismo tem produzido uma nova geração de políticas públicas. Se as primeiras estavam voltadas as questões básicas, até mesmo de sobrevivência dos indivíduos, estas carregam em sim tons mais progressistas. E é neste novo cenário que se insere a audiodescrição, a qual entendemos estar em processo de construção conceitual e política.

Um dos eventos que talvez nos ajuda a compreender esta nova conjuntura foi a Conferência das Nações Unidas sobre Desenvolvimento Sustentável, a Rio+20, realizada de 13 a 22 de junho de 2012, na cidade do Rio de Janeiro, assim denominada porque marcou os vinte anos de realização da Conferência das Nações Unidas sobre Meio Ambiente e Desenvolvimento, a Rio 92 e contribuiu para definir a agenda do desenvolvimento sustentável para as próximas décadas, onde uma de suas característica mais significativas foi o investimento em medidas de acessibilidade e também a forma como se deu a participação das pessoas com deficiência, seja nos diversos espaços como nas decisões finais.

A partir destas reflexões iniciais, o presente trabalho pretende abordar justamente a audiodescrição como uma nova política pública e sua relação com a educação ambiental, compreendendo que, pessoas com deficiência, como sujeitos de direitos, precisam estar inseridos nos debates ambientais que hoje, são decisivos na definição dos rumos do desenvolvimento de todos os países do mundo. Conforme Borges: "As lacunas existentes entre sustentabilidade, acessibilidade e direitos humanos demonstram a dificuldade de incorporação, de forma articulada, de temas transversais no contexto das políticas públicas” (2012, p. 291).

A partir destas reflexões iniciais, o presente trabalho pretende abordar justamente a audiodescrição como uma nova política pública e sua relação com a educação ambiental, compreendendo que, pessoas com deficiência, como sujeitos de direitos, precisam estar inseridos nos debates ambientais que hoje, são decisivos na definição dos rumos do desenvolvimento de todos os países do mundo. Por outro lado, é preciso destacar que tem aumentado gradativamente as catástrofes naturais, exigindo assim também, que pensemos no acesso prioritário destes públicos nestas situações. Evidencia-se que, ambos os temas estão abarcados no contexto da ideia de transversalidade.

Acessível, Habitação de Interesse Social Acessível) e de Atendimento à Pessoa com Deficiência (Inserção das Pessoas com Deficiência no Mercado de Trabalho, Concessão de Órteses e Próteses, Campanhas Educativas). Entre as ações na área da educação, estava o apoio à adaptação das salas de aula para a universalização do ensino inclusivo.

${ }^{5}$ O Plano Nacional dos Direitos da Pessoa com Deficiência - Viver sem Limite, lançado em 17 de novembro de 2011 pelo Governo Federal, foi elaborado com a participação de mais de 15 ministérios e do Conade, e prevê um investimento total no valor de R \$ 7,6 bilhões até 2014 . 
Em um primeiro momento, será abordado a construção teórica e política da audiodescrição, a partir de seus marcos legais e principais agentes de mediação. Também discutiremos as políticas de educação ambiental buscando relacionar com a perspectiva inclusiva, estabelecendo recorte dos públicos e ações as quais podemos inserir a audiodescrição como mais uma ferramenta pedagógica em sua implementação. Para isso, analisaremos os documentos, fatos históricos e trajetórias as quais estes temas se constroem politicamente no âmbito público. Neste sentido, será fundamental também estabelecer uma relação com a ideia de institucionalidade como um atributo destas conquistas.

\section{A Construção Teórica e Política da Audiodescrição}

O conceito e as ideias de políticas públicas têm diferentes vertentes teóricas, que são carregados de questões históricas, sociais e culturais. De uma forma geral, está relacionado ao conjunto de ações e decisões do governo para a solução de problemas e demandas da sociedade, que podem ter como resultados, ações, metas e planos. Conforme Souza:

Pode-se, então, resumir política pública como o campo do conhecimento que
busca, ao mesmo tempo, "colocar o governo em ação" e/ou analisar essa ação
(variável independente) e, quando necessário, propor mudanças no rumo ou
curso dessas ações (variável dependente). A formulação de políticas públicas
constitui-se no estágio em que os governos democráticos traduzem seus
propósitos e plataformas eleitorais em programas e ações que produzirão
resultados ou mudanças no mundo real (2006, p. 20-45)

Neste aspecto, a audiodescrição é parte de um cenário de construção teórica e política, sendo estabelecida e afirmando-se no contexto das políticas públicas a partir dos documentos normativos, teses, dissertações, mas também, e de forma bastante significativa, pela ação dos sujeitos na compreensão de que para além de um recurso, é um direito, e assim, merece ser disputado socialmente.

Ela surge para dar o sentido de igualdade de oportunidades e reduzir as barreiras, ou seja, tornar acessível, a participação de determinados grupos sociais, prioritariamente, pessoas cegas e com baixa visão, em atividades as quais o seu impedimento no corpo encontra uma barreira no ambiente, no caso, o fato de não enxergar. Isso pode se dar nas diferentes políticas públicas educação, cultura, trabalho, assistência social, turismo, esporte e lazer, segurança, justiça dentre outras.

Para Sassaki (2009), há seis tipos de acessibilidade, para além da arquitetônica, que é a mais comum e popularizada por conta da sua relação com um aspecto perceptivel no ponto de vista visual. Para o autor, há ainda, pelo menos, outras cinco dimensões - a atitudinal, a 
metodológica, a instrumental, a programática e a comunicacional.

ACESSIBILIDADE ARQUITETÔNICA: É a forma de acessibilidade sem barreiras ambientais físicas, nas residências, nos edifícios, nos espaços urbanos, nos equipamentos urbanos, nos meios de transporte individual ou coletivo; ACESSIBILIDADE ATITUDINAL: Refere-se à acessibilidade sem preconceitos, estigmas, estereótipos e discriminações, em relação às pessoas em geral; ACESSIBILIDADE COMUNICACIONAL: É a acessibilidade que se dá sem barreiras na comunicação interpessoal (face a face, língua de sinais), escrita (jornal, revista, livro, carta, apostila etc., incluindo textos em braile, uso do computador portátil) e virtual (acessibilidade digital). ACESSIBILIDADE INSTRUMENTAL: Sem barreiras nos instrumentos, utensílios e ferramentas de estudo (escolar), de trabalho (profissional), de lazer e recreação (comunitária, turística, esportiva etc.); ACESSIBILIDADE METODOLÓGICA: Sem barreiras nos métodos e técnicas de estudo (escolar), de trabalho (profissional), de ação comunitária (social, cultural, artística etc.), de educação dos filhos (familiar). ACESSIBILIDADE PROGRAMÁTICA: Sem barreiras - muitas vezes imperceptíveis - embutidas em políticas públicas (leis, decretos, portarias etc.), normas e regulamentos (institucionais, empresariais etc.). (SASSAKI, 2009, s.p.)

Conforme Motta e Romeu Filho (2010):

A audiodescrição é um recurso de acessibilidade que amplia o entendimento das pessoas com deficiência visual em eventos culturais, gravados ou ao vivo, como: peças de teatro, programas de TV, exposições, mostras, musicais, óperas, desfiles e espetáculos de dança; eventos turísticos, esportivos, pedagógicos e científicos tais como aulas, seminários, congressos, palestras, feiras e outros, por meio de informação sonora. Além das pessoas com deficiência visual, a audiodescrição amplia também o entendimento de pessoas com deficiência intelectual, idosos e disléxicos. (MOTTA e ROMEU FILHO, 2010, p. 11)

A audiodescrição está ancorada academicamente, nos estudos da tradução, portanto, pode ser entendida como uma medida de acessibilidade comunicacional. É assim, uma ferramenta de inclusão, que para Sassaki (2009), pode ser entendida como um paradigma de sociedade, um processo pelo qual os sistemas sociais comuns são tornados adequados para toda a diversidade humana com a participação das próprias pessoas na formulação e execução dessas adequações. Segundo Jimmenez-Hurtado:

la audiodescripción es un tipo de información en forma de traducción de imágenes a palabras; del mismo modo, la subtitulación para sordos es una traducción del lenguaje oral, presente en el texto audiovisual, a lenguaje escrito con determinado tipo de restricciones o adaptaciones que lo convierten en un tipo de texto específico (2010, p. 14).

Para Franco e Silva (2010), a prática de se descrever o mundo visual para pessoas nãovidentes é imemorial. Segundo as autoras, enquanto atividade técnica, a audiodescrição nasce na metade da década de 70 nos Estados Unidos, a partir das ideias desenvolvidas por Gregory 
Frazier em sua dissertação de mestrado, intitulada "Master of Arts" anos 80 (FRANCO e SILVA, 26).

No Brasil, a sanção da Lei $\mathrm{n}^{\circ}$ 10.098/2000, dois artigos relacionam-se diretamente com este recurso. $\mathrm{O}$ art. $2^{\circ}$ trouxe a definição de "barreiras nas comunicações" e o art. 17. Destaca o papel do poder na promoção da eliminação de barreiras na comunicação (BRASIL, 2000).

Em 2004, quatro anos após a sanção, o regulamento da referida legislação se deu através do Decreto $\mathrm{n}^{\circ}$ 5.296, que em seu artigo 52 determinou a adaptação dos aparelhos televisores de modo a poderem ser utilizados por pessoas com deficiência e o artigo 53 atribuiu à Agência Nacional de Telecomunicações (ANATEL) a competência para regulamentar as questões referentes à acessibilidade na programação veiculada pelas emissoras de televisão, entre elas: closed caption ou legenda oculta, audiodescrição e janela para intérprete de Língua Brasileira de Sinais (LIBRAS) ${ }^{7}$.

Em 2005 foi assinado o Decreto $n^{\circ} 5.371^{8}$, que reformulou e estabeleceu as competências do Ministério das Comunicações e da ANATEL, no que se refere aos serviços de transmissão e retransmissão da programação de televisão, o que exigiu assim que o artigo 53 do Decreto 5.296 também fosse reformulado. Também neste mesmo ano, em outubro, o Comitê Brasileiro de Acessibilidade da Associação Brasileira de Normas Técnicas (ABNT) publicou a Norma Brasileira (NBR) 15290 que tratou da "Acessibilidade em Comunicação na Televisão" trazendo o conceito de "descrição em áudio de imagens e sons" como uma narração descritiva de imagens.

Em dezembro de 2005 foi assinado ainda o Decreto $n^{\circ}$ 5.645, que deu nova redação ao Artigo 53 do Decreto $\mathrm{n}^{\circ}$ 5.296, atribuindo ao Ministério das Comunicações a responsabilidade pela regulamentação das diretrizes de acessibilidade na programação das emissoras de televisão.

Em abril de 2006 foi assinado o Decreto $n^{\circ} 5.762 / 2006$, que prorrogou por 60 dias o prazo para o cumprimento do que determinava o Decreto $n^{\circ} 5.645 / 2005$, ou seja, ampliou o prazo para o Ministério das Comunicações publicar a regulamentação do artigo 53 do Decreto $\mathrm{n}^{\circ}$ $5.296 / 2004$

Em 2008, o Ministério das Comunicações publica a Portaria n 466/2008, que estabelece:

Art. $1^{\circ}$ Conceder o prazo de noventa dias, contado da data de publicação desta Portaria, para que as exploradoras de serviço de radiodifusão de sons e imagens e de serviço de retransmissão de televisão (RTV) passem a veicular, na

\footnotetext{
${ }^{6}$ Outras questões históricas: http://audiodescricao.com.br/ad/historico-resumido/

${ }^{7}$ A LIBRAS, foi reconhecida oficialmente pela Nação brasileira como a língua oficial com a publicação das Leis $n^{\circ}$ $10.436 / 2002$ e 10.098/2000, que foram regulamentadas pelo Decreto $\mathrm{n}^{\circ}$ 5.626/2005.

${ }^{8}$ Disponível em: https://www.planalto.gov.br/ccivil_03/_Ato2004-2006/2005/Decreto/D5371.htm
} 
programação por elas exibidas, o recurso de acessibilidade de que trata o subitem 3.3 da Norma Complementar $\mathrm{n}^{\mathrm{o}} 01 / 2006$, aprovada pela Portaria $\mathrm{n}^{\mathrm{o}}$ 310 , de 27 de junho de 2006, ficando mantidas as demais condições estabelecidas no subitem 7.1 da mesma Norma. ${ }^{9}$

Em 2009, a então Coordenadoria Nacional de Integração da Pessoa Portadora de Deficiência (CORDE) realizou reunião técnica com a participação de diversos audiodescritores e instituições representativas de pessoas com deficiência para discutir as questões formuladas pelo Ministério das Comunicações na Portaria nº 661/2008, ocorrendo por conta disto, manifestação contrária do Conselho Nacional dos Direitos da Pessoa com Deficiência (Conade).

Em 2010 a Subsecretaria Nacional de Promoção dos Direitos da Pessoa com Deficiência, antiga CORDE, promoveu nova reunião técnica para a qual foram convidados diversos audiodescritores, entidades representativas de pessoas com deficiência, entidades representativas das emissoras de televisão, diversos órgãos do governo federal, dentre outros., culminando na edição, pelo Ministério das Comunicações da Portaria nº 188.

Em junho de 2011, em uma iniciativa conjunta do Ministério das Comunicações e da Secretaria de Direitos Humanos da Presidência da República, foi anunciado o início da audiodescrição na TV. O Sistema Brasileiro de Televisão (SBT) foi responsável pela primeira transmissão de um programa audiodescrito após o início da obrigação estabelecida pela Portaria $n^{\circ}$ 188. Logo em seguida, a TV Globo também anunciou os programas que teriam o recurso.

Tramitam na Câmara dos Deputados um conjunto de propostas abordando esta temática, sendo que um dos mais importantes, é o Projeto de Lei $\mathrm{n}^{\mathrm{o}} 5.156 / 2013^{10}$, de autoria de Eduardo Barbosa (PSDB/MG) que dispõe sobre a regulamentação do exercício da profissão de audiodescritor. Na proposta a audiodescrição é definida como:

Um instrumento tradutório de acessibilidade comunicacional que consiste no conjunto de técnicas e habilidades aplicadas, com objetivo de proporcionar uma narração descritiva em áudio para ampliação do entendimento, de imagens estáticas ou dinâmicas, textos e origem de sons, despercebidos ou incompreensíveis especialmente sem o uso da visão.

Um dos capítulos mais recente desta trajetória tem como elemento a Instrução Normativa $\mathrm{n}^{\mathrm{o}}$ 116/2014 da Agência Nacional do Cinema (ANCINE) ${ }^{11}$ que tratou sobre as normas gerais e critérios básicos de acessibilidade a serem observados por projetos audiovisuais financiados

\footnotetext{
${ }^{9}$ Disponível em: http://www.blogdaaudiodescricao.com.br/2010/02/audiodescricao-portaria-466-do.html - acessado em 25 de julho de 2015.

${ }^{10}$ Disponível em: https://www.google.com.br/webhp?sourceid=chrome-instant\&ion=1\&espv=2\&ie=UTF8\#q=pL+AUDIODESCRI\%C3\% 87\%C3\%830+CAMARA+EDUARDO+BARBOSA.

${ }^{11}$ Disponível em: http://www.ancine.gov.br/legislacao/instrucoes-normativas-consolidadas/instru-o-normativa-n116-de-18-de-dezembro-de-2014
} 
com recursos públicos federais geridos pela Agência. $\mathrm{O}$ referido documento foi colocado em consulta pública assim como a ANATEL fez o mesmo com a proposta de Regulamento Geral de Acessibilidade em Telecomunicações de interesse coletivo (Consulta Pública $\mathrm{n}^{\mathbf{o}}$ 18, agosto/2015) $)^{12}$ materializado na Resolução $n^{\circ} 667$, de 30 de maio de $2016 .{ }^{13}$

Ressaltamos ainda que o Estatuto da Pessoa com Deficiência (Lei Brasileira da Inclusão) ${ }^{14}$ trouxe dentre seus 127 artigos, dois relacionados a audiodescrição. O primeiro deles, trata sobre os serviços de radiodifusão de sons e imagens (Art. 67). O outro, dispõe da promoção da capacitação de profissionais habilitados em Braille, audiodescrição, estenotipia e legendagem (Art. 73). Vale destacar que existe, neste período, conforme pode ser observado na linha do tempo do marco legal da audiodescrição (Tabela 1), uma determinada prioridade nas questões da comunicação, sobretudo na TV e no Cinema.

\section{Tabela 1 - Linha do tempo da Audiodescrição no Brasil}

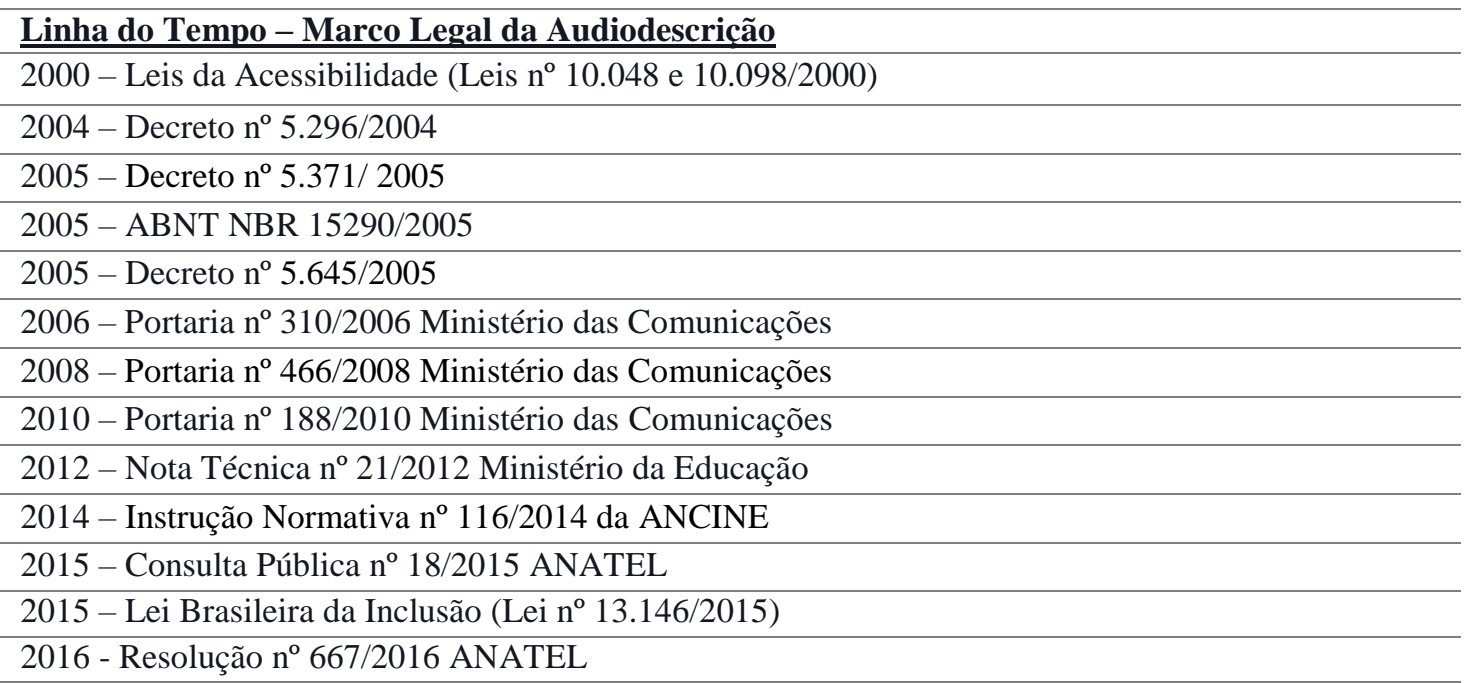

Entre cada novo documento, há um conjunto de embates estabelecidos, com forças que disputam espaços distintos de ordem econômica, social e cultural. As políticas públicas têm uma tarefa de conciliar os interesses coletivos dos privados. A arte desta construção, é permeada por diferentes atores, que conforme as movimentações, são estabelecidas complexas alianças que envolve os deslocamentos nos territórios por onde transitam os atores sociais.

O Conade, na função de espaço de controle e participação da sociedade e a CORDE, depois Secretaria Nacional de Promoção dos Direitos da Pessoa com Deficiência (SNPD) estiveram presentes neste processo de forma ativa, nas disputas estabelecidas no âmbito político.

\footnotetext{
${ }^{12}$ Disponível em:

http://sistemas.anatel.gov.br/SACP/Contribuicoes/TextoConsulta.asp?CodProcesso=C1871\&Tipo=1\&Opcao=anda mento

${ }^{13}$ Disponível em: http://www.anatel.gov.br/legislacao/resolucoes/2016/905-resolucao-n-667

${ }^{14}$ Disponível em: http://www.planalto.gov.br/ccivil_03/_Ato2015-2018/2015/Lei/L13146.htm
} 
O Conselho, em 2009 emitiu uma nota de exigibilidade da audiodescrição, onde solicitou a implementação da Convenção sobre Direitos das Pessoas com Deficiência e o cumprimento, por parte do Ministério das Comunicações da Portaria n ${ }^{\circ}$ 310/2006 em seu inteiro teor, pondo fim à suspensão da exigibilidade da mesma, e que garantisse a audiodescrição para os cidadãos brasileiros, sem mais demoras e sem supressão de direitos. No mesmo ano, foi enviado um ofício ao ministro solicitando que fossem adotadas as medidas que visem respeitar o direito que as pessoas com deficiência visual possuem de obter todas as informações veiculadas pelas emissoras de televisão do País e suas retransmissoras, direito este assegurado pela Convenção da ONU sobre os Direitos das Pessoas com Deficiência, ratificada pelo Congresso Nacional com força de emenda Constitucional. Ambos os documentos, percebe-se a influência da Convenção como um argumento consistente.

Analisando o Relatório Final da III ${ }^{\mathrm{a}}$ Conferência Nacional dos Direitos da Pessoa com Deficiência $^{15}$, ocorrida em 2012, constata-se que foram apresentadas 10 propostas onde a audiodescrição esteve presente (Quadro 1), em quatro dos nove eixos da Conferência: Esporte, cultura e lazer (1), acessibilidade (2), comunicação (6) e segurança e acesso à justiça (1) ${ }^{16}$. Nas Conferências anteriores, apenas na segunda, ocorrida em 2008, houve apenas duas propostas e somente no eixo acessibilidade dos cinco daquele evento. O que observamos é que houve uma evolução na discussão da sociedade, evidente na apresentação de reivindicações na última Conferência, que inclusive, foi a primeira que ofertou o recurso ao público presente.

\footnotetext{
${ }^{15}$ Disponível em: http://www.pessoacomdeficiencia.gov.br/app/sites/default/files/publicacoes/livro-relatorio-3aconferencia-final_0.pdf

${ }^{16}$ As conferências são espaços públicos de debates, mecanismos institucionais de democracia participativa. São grandes fóruns organizados, em que os diversos segmentos da sociedade debatem, por meio de metodologia específica, todas as políticas públicas do país que sejam referentes aos temas discutidos. A etapa nacional é resultante de outras diversas conferências realizadas em nível local, municipal, regional ou estadual. Entre os anos de 2006 e 2012 ocorreram três conferências nacionais dos direitos da pessoa com deficiência que mobilizaram milhares de pessoas, entidades, conselhos, órgãos gestores e culminaram em centenas de propostas. A I Conferência Nacional dos Direitos das Pessoas com Deficiência foi realizada em Brasília entre os dias 12 e 15 de maio de 2006 e teve como tema "Acessibilidade: Você também tem compromisso". Nela, foi lançada a campanha "Acessibilidade Siga essa Ideia", que por meio de diversas ações nos mais variados campos buscou sensibilizar a população sobre o tema. A II Conferência Nacional ocorreu de 1 a 4 de dezembro de 2008, ano especialmente emblemático para o movimento político das pessoas com deficiência no Brasil, pois marcou os 60 anos da Declaração Universal dos Direitos Humanos, além de ser o ano de ratificação da Convenção sobre os Direitos das Pessoas com Deficiência da ONU pelo país. Com o tema "Inclusão, participação e desenvolvimento: Um novo jeito de avançar", a Conferência contou com a participação de cerca de 2 mil pessoas e teve a questão da inclusão como pano de fundo dos debates. A III Conferência Nacional aconteceu entre os dias 3 e 6 de dezembro de 2012, com o tema "Um olhar através da Convenção sobre os Direitos das Pessoas com Deficiência da ONU: Novas perspectivas e desafios". Esta foi a primeira Conferência pós-ratificação da Convenção da ONU no país, colocando-a como eixo central de todo o processo de debates.
} 
Quadro 1 - Propostas da III ${ }^{\mathrm{a}}$ Conferência Nacional dos Direitos da Pessoa com Deficiência que contemplaram audiodescrição

\begin{tabular}{|c|c|}
\hline \multicolumn{2}{|r|}{ III ${ }^{a}$ Conferência Nacional dos Direitos da Pessoa com Deficiência } \\
\hline Eixo & Proposta \\
\hline $\begin{array}{l}\text { Esporte, cultura e } \\
\text { lazer }\end{array}$ & $\begin{array}{l}\text { 2) Adequar e criar espaço cultural multiuso considerando o desenho universal, nas três } \\
\text { esferas de governo, bem como promover eventos culturais com participação das Pessoas } \\
\text { com Deficiência com o objetivo de promover a inclusão social. Fazer cumprir a lei de } \\
\text { acessibilidade universal em todas as atividades e eventos culturais organizadas por } \\
\text { empresas, órgãos e instituições com ofertas de serviços turísticos como, por exemplo, } \\
\text { interpretação em LIBRAS, material promocional em Braille, fonte ampliada, tecnologias } \\
\text { assistivas e acessibilidade em língua de sinais, audiodescrição, entre outros, } \\
\text { possibilitando assim, que as informações turísticas sejam disponibilizadas através da } \\
\text { LIBRAS e sistema de voz em passeios, roteiros, visitações, Mostras e Museus, entre } \\
\text { outros. }\end{array}$ \\
\hline Acessibilidade & $\begin{array}{l}\text { 15) Garantir em toda a publicidade de governo (serviços públicos) a inserção de recursos } \\
\text { de acessibilidade com janela com intérprete de LIBRAS, legenda e audiodescrição. }\end{array}$ \\
\hline Acessibilidade & $\begin{array}{l}\text { 40) Dispor de meios de informação tecnológicos, maquetes tácteis, mapas em } \\
\text { autorrelevo, audiodescrição, interpretes de LIBRAS, legendas e tecnologias que por } \\
\text { ventura venham a ser criadas nos equipamentos culturais como museus, teatros, cinemas, } \\
\text { bibliotecas, galerias de arte, parques, jardins botânicos, zoológicos e assemelhados } \\
\text { prevendo rotas acessíveis para usuários de cadeiras de rodas. }\end{array}$ \\
\hline Comunicação & $\begin{array}{l}\text { 3) Garantir a acessibilidade para pessoas com deficiência, em tempo integral, nos } \\
\text { diversos meios de comunicação de massa, como televisão, mídia impressa, cinema e } \\
\text { internet, inclusive governamentais. A acessibilidade deve abranger contratação e } \\
\text { capacitação de pessoal para sua elaboração, dentro do que estabelece o Art. } 47 \text { do } \\
\text { Decreto } N^{\circ} \text { 5.296/2004; utilizar recursos como braile, audiodescrição, legendas e janelas } \\
\text { de interpretação de LIBRAS, com tamanho maior e velocidade apropriada, caracteres } \\
\text { ampliados, closed caption, etc., inclusive na internet, com atualização constante dos } \\
\text { recursos de tecnologia assistiva, de modo a atender a todas as especificidades das } \\
\text { pessoas com deficiência. }\end{array}$ \\
\hline Comunicação & $\begin{array}{l}\text { 9) Garantir a acessibilidade em todos os locais abertos ao público, incluindo instituições } \\
\text { privadas que prestam serviços públicos e meios de transporte público de uso coletivo, } \\
\text { com o cumprimento da legislação quanto à capacitação, a sinalização e acessibilidade na } \\
\text { comunicação da pessoa surda, com deficiência auditiva, surdocega, cega, com baixa } \\
\text { visão e com deficiência múltipla. Para tanto, devem ser utilizados recursos como } \\
\text { legenda, janela de LIBRAS, intérprete, guia intérprete, instrutor mediador, identificação } \\
\text { em braile, caracteres ampliados, audiodescrição, sinalização sonora em semáforos, } \\
\text { disponibilização de número de celular para envio de mensagem e outros recursos de } \\
\text { comunicação necessários à pessoa com deficiência. }\end{array}$ \\
\hline Comunicação & $\begin{array}{l}\text { 10) Garantir a acessibilidade para pessoas com deficiência nas diversas atividades } \\
\text { sociais, inclusive culturais, religiosas, profissionais, acadêmicas, etc., tornando } \\
\text { obrigatória a utilização de recursos como braile, audiodescrição, legendas e janelas de } \\
\text { interpretação de LIBRAS, caracteres ampliados, closed caption etc., de modo a atender a } \\
\text { todas as especificidades das pessoas com deficiência. }\end{array}$ \\
\hline Comunicação & $\begin{array}{l}\text { 15) Realizar uma série de medidas voltadas à educação e capacitação relacionada à } \\
\text { acessibilidade, entre elas: formação do profissional em audiodescrição e tradutores e } \\
\text { intérpretes de LIBRAS, com realização de concursos públicos; capacitação periódica de } \\
\text { todos os agentes públicos para atender pessoas com deficiência ou mobilidade reduzida, } \\
\text { incluindo LIBRAS e audiodescrição; formação e capacitação em acessibilidade para } \\
\text { profissionais de diferentes áreas; inserção de disciplinas obrigatórias de acessibilidade e } \\
\text { direitos das pessoas com deficiência em todos os currículos acadêmicos de universidades } \\
\text { públicas e privadas; apoio à pesquisa na busca por soluções em acessibilidade nas } \\
\text { instituições de ensino, mediante instrumentos, como parcerias público-privadas e outros. }\end{array}$ \\
\hline Comunicação & $\begin{array}{l}\text { 21) Promover ações que garantam a fiscalização, por parte do MP e ANATEL, ao } \\
\text { cumprimento dos Decretos } n^{\circ} 5.626 / 2005 \text { e n }{ }^{\circ} 5.296 / 2004 \text {, NBR } 15599 \text {, NBR } 15290 \text { e a } \\
\text { NBR } 9050 \text { sobre a audiodescrição/interpretação em LIBRAS em todos os meios de } \\
\text { comunicação, }\end{array}$ \\
\hline
\end{tabular}




\begin{tabular}{|l|l|}
\hline Comunicação & $\begin{array}{l}\text { 22) Garantir a acessibilidade para pessoas com deficiência em toda a comunicação } \\
\text { governamental (federal, estadual e municipal) com destinação pública, com utilização de } \\
\text { recursos atualizados como braile, audiodescrição, legendas e janelas de interpretação de } \\
\text { LIBRAS, caracteres ampliados e closed caption etc., de modo a atender a todas as } \\
\text { especificidades das pessoas com deficiência. A acessibilidade deve estar prevista em } \\
\text { norma específica, baseada na Lei de Acesso à Informação e no quantitativo de pessoas } \\
\text { com deficiência em cada esfera de poder }\end{array}$ \\
\hline $\begin{array}{l}\text { Segurança e Acesso a } \\
\text { Justiça }\end{array}$ & $\begin{array}{l}\text { 27) Elaboração de cartilha acessível com a Convenção da ONU, legislação correlata, } \\
\text { orientação relativa aos direitos das pessoas com deficiência contendo indicação dos } \\
\text { locais para reclamações e denúncias de violações, amplamente divulgada em nível } \\
\text { municipal, com todos os recursos de acessibilidade, inclusive audiodescrição. }\end{array}$ \\
\hline
\end{tabular}

Já no Relatório Final da IV $^{\mathrm{a}}$ Conferência Nacional dos Direitos da Pessoa com Deficiência, ocorrida em 2016 (Quadro 2), o termo audiodescrição é citado em uma diretriz e em uma moção de apoio, demonstrando o avanço do tema no âmbito dos discursos das políticas públicas.

\section{Quadro 2 - Propostas da IV ${ }^{a}$ Conferência Nacional dos Direitos da Pessoa com Deficiência que contemplaram audiodescrição.}

\begin{tabular}{|l|l|}
\hline \multicolumn{2}{|l|}{ IV $^{\text {a Conferência Nacional dos Direitos da Pessoa com Deficiência }}$} \\
\hline Eixo & Proposta \\
\hline Diretriz 5 & $\begin{array}{l}\text { Elaborar instrumento específico e acessível para comunicação, tipo cartilha, } \\
\text { contendo a Convenção da ONU, legislação correlata, orientação relativa aos direitos das } \\
\text { pessoas com deficiência, seus benefícios previdenciários, bem como a indicação dos } \\
\text { locais para reclamações e denúncias de violações, amplamente divulgada, com todos os } \\
\text { recursos de acessibilidade inclusive audiodescrição }\end{array}$ \\
\hline Moção & Moção em Defesa da Audiodescrição \\
\hline
\end{tabular}

\section{A Educação Ambiental no Brasil}

A educação ambiental, assim como a audiodescrição, possui um processo de construção, e inegavelmente de institucionalização como política pública a partir de luta social, ou seja, dos educadores e militantes que também construíram suas formas de estabelecer esta política pública. A educação ambiental nasce como um processo educativo que conduz a um saber ambiental materializado nos valores éticos e nas regras políticas de convívio social e de mercado (SORRENTINO et al., 2005).

O início desta construção institucionalizada ocorre no ano 1999, com a promulgação da Lei $n^{\circ} 9.795$ que instituiu a Política Nacional de Educação Ambiental (PNEA), criou o Órgão Gestor $(\mathrm{OG})^{17}$. Conceitualmente, a legislação propôs a educação ambiental como:

\footnotetext{
${ }^{17}$ O Órgão Gestor da Política Nacional de EA foi criado a partir do artigo 14 da Lei Federal no 9.795 , de 27 de abril de 1999.
} 
Processos por meio dos quais o indivíduo e a coletividade constroem valores sociais, conhecimentos, habilidades, atitudes e competências voltadas para a conservação do meio ambiente, bem de uso comum do povo, essencial à sadia qualidade de vida e sua sustentabilidade (Art. $1^{\circ}$ ).

Outro documento significativo a ser referenciado é o Plano Nacional de Educação $(\mathrm{PNE})^{18}$ - 2001-2010, aprovado pelo Congresso Nacional (Lei 10.172/2001), o qual, além de cumprir uma determinação da Lei de Diretrizes e Bases da Educação Nacional (LDBEN) em seu artigo 87, fixou diretrizes, objetivos e metas para o período de dez anos, garantindo coerência nas prioridades educacionais para este período. Nos objetivos e metas para o ensino fundamental e ensino médio propôs a educação ambiental, tratada como tema transversal. Este plano discutido com todos os setores da sociedade envolvidos na educação representou um avanço da questão ambiental no universo da educação.

Em 2002 foi editado o Decreto $\mathrm{n}^{\circ}$ 4.281, que regulamentou a PNEA, criou o Comitê Assessor $(\mathrm{CA})^{19}$ e previu a existência da Comissões Interinstitucionais de Educação Ambiental (CIEAs) nos Estados, que vão moldando as estratégicas de implementação do Programa Nacional de Educação Ambiental (PRONEA), que de acordo com o MEC, dividem-se em três eixos: Gestão e articulação institucional, Formação de educadores e Educomunicação.

A primeira década dos anos 2000, o país apresentou um conjunto de programas e projetos, que foram resultado de um período de discussões no mundo inteiro, com destaque ao legado do Fórum Social Mundial ${ }^{20}$, a Cúpula do Clima e a Rio+10, que estimularam o protagonismo e o controle social, tendo como referências no âmbito da educação ambiental as Conferências Nacional ${ }^{21}$ e Infanto-juvenil do Meio Ambiente e um marco legal que vem constituindo-se desde 1981.

Este conjunto de ações constitui o marco legal e político da educação ambiental no Brasil, que de alguma forma influencia os espaços educativos, direta ou indiretamente, conforme a Tabela 2, onde podemos observar na linha do tempo, iniciando em 1981, com a Política Nacional do Meio Ambiente (PNMA) até 2014.

\footnotetext{
${ }^{18}$ A construção deste plano atendeu aos compromissos assumidos pelo Fórum Nacional em Defesa da Escola Pública. Disponível em: http://portal.mec.gov.br/arquivos/pdf/pne.pdf

${ }^{19} \mathrm{O}$ Comitê Assessor foi criado com o artigo $4^{\circ}$ do Decreto $\mathrm{n}^{\circ} 4.281 / 2002$, com a função de assessorar o Órgão Gestor no planejamento e avaliação de diretrizes e ações relativas ao processo de implementação da PNEA.

${ }^{20}$ O Fórum Social Mundial é um espaço de debate democrático de ideias, aprofundamento da reflexão, formulação de propostas, troca de experiências e articulação de movimentos sociais, redes, ONGs e outras organizações da sociedade civil que se opõem ao neoliberalismo e ao domínio do mundo pelo capital e por qualquer forma de imperialismo. O primeiro FSM em 2001 foi seguido de um processo mundial de busca da construção de alternativas às políticas neoliberais. Esta definição está consagrado na Carta de Princípios do FSM.

${ }^{21}$ As conferências de meio ambiente são espaços de interlocução da sociedade nas políticas de meio ambiente.
} 
Tabela 2 - Linha do Tempo da Educação Ambiental no Brasil

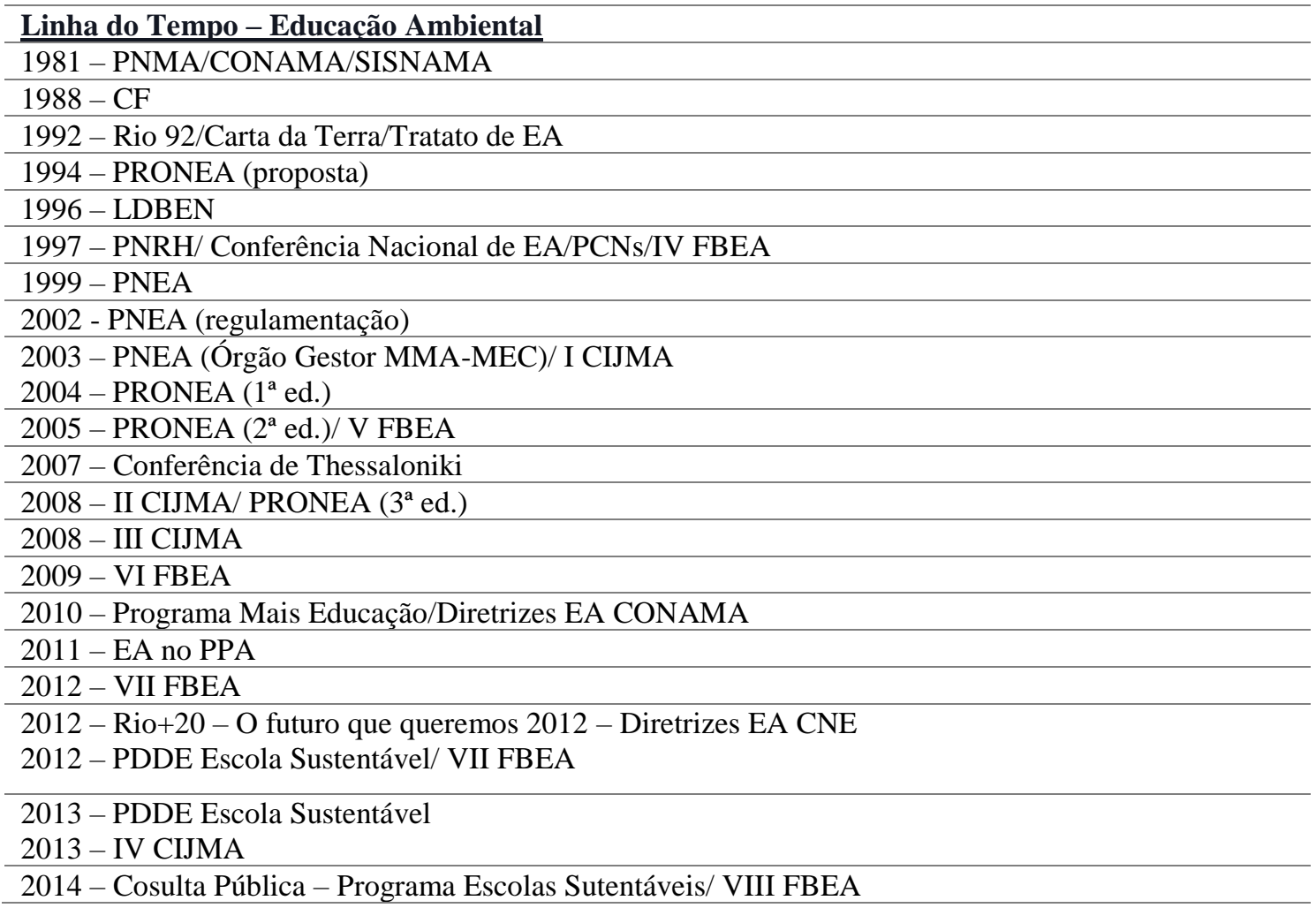

Percebe-se assim, que a educação ambiental vem afirmando-se em duas vertentes - uma normativa, a partir do conjunto de leis, decretos, portarias, programas e outros instrumentos jurídicos e governamentais, - e outra, baseada em documentos internacionais. O que há em comum nestes dois pontos, e que também é presente na política da pessoa com deficiência, é a atuação direta da sociedade civil em seus processos de construção a partir do protagonismo efetivo.

O Projeto de Lei $n^{\circ} 8.035 / 2010^{22}$, que estabeleceu o PNE (2011-2020), apresentou dez diretrizes objetivas e vinte metas, seguidas das estratégias específicas de concretização para cada uma delas. Em seu artigo $2^{\circ}$, a sétima diretriz refere-se à "promoção da sustentabilidade socioambiental". Ao todo, foram apresentadas 2.915 emendas $^{23}$, sendo destas, apenas quatro relacionadas diretamente a EA e sustentabilidade.

A Comissão Especial do PNE na Câmara dos Deputados aprovou o texto principal em 13 de junho de 2012, as vésperas da Rio+20, resumindo a educação ambiental a apenas a uma diretriz, não aparecendo em nenhuma meta ou objetivo. No texto final, a educação ambiental

\footnotetext{
${ }^{22}$ Disponível em: http://portal.mec.gov.br/index.php?option=com_content\&view=article\&id=16478\&Itemid=1107

${ }^{23}$ Conforme Relatório da Comissão Especial do Plano Nacional de Educação da Câmara dos Deputados. Disponível em: http://www2.camara.gov.br/atividade-legislativa/comissoes/comissoes-temporarias/especiais/54a-legislatura/pl8035-10-plano-nacional-de-educacao/arquivos-destaque/relatorio-de-emendas-ao-pne
} 
restringiu-se a uma das diretrizes "X - promoção dos princípios do respeito aos direitos humanos, à diversidade e à sustentabilidade socioambiental” (BRASIL, 2014).

A Câmara dos Deputados também está analisando dois Projetos de Lei referente a educação ambiental. O no 3215/2012 ${ }^{24}$ busca instituir o Fundo Nacional de Educação Ambiental (FNEA. Já o projeto $\mathrm{n}^{\text {o }} 4361 / 2012^{25}$, altera a Lei $\mathrm{n}^{\circ}$ 9.795/1999 para direcionar parte dos "Recursos obtidos pela aplicação das multas ambientais, à Implementação das Políticas públicas e Ações em Educação Ambiental". No senado federal, está em andamento na Comissão de Meio Ambiente, Defesa do Consumidor e Fiscalização e Controle (CMA) o Projeto de Lei ${ }^{\circ}$ 221/2015, que estabelece a criação da disciplina de Educação Ambiental nas escolas de ensino fundamental e médio. De autoria do senador Cássio Cunha Lima (PSDB-PB), o projeto modifica a LDBEN para transformar o tema da educação ambiental em uma disciplina obrigatória para os alunos de todas as séries dos níveis fundamental e médio.

O MEC homologou o parecer $n^{\circ} 14 / 2012^{26}$ do CNE que contém a Resolução $n^{\circ} 02^{27}$, de 15 de junho de 2012, que estabeleceu as Diretrizes Curriculares Nacionais da Educação Ambiental (DCNEA) para as todas as escolas e instituições de ensino do País. A homologação ocorreu durante a Rio+20. Conforme nota da CGEA (Coordenação Geral de Educação Ambiental) ${ }^{28}$ :

O texto da resolução que, aprovada, passou a integrar o marco legal da Educação Ambiental no Brasil, apresentando-se como referência para a promoção da Educação Ambiental em todos os níveis e modalidades do ensino formal.

No ponto de vista institucional, a gestão da educação ambiental cabe à Diretoria de Educação Ambiental (DEA) do MMA e a CGEA do MEC com apoio financeiro fornecido pelo FNMA do MMA ou pelo Fundo Nacional de Desenvolvimento da Educação (FNDE) do MEC, entidades que, respectivamente atendem a essas demandas para a EA informal/não- formal e para o âmbito escolar.

A partir desta breve contextualização histórica dos processos políticos, identificamos que a educação ambiental na relação com as políticas públicas tem, portanto, apresentado significativos avanços, partindo de citações particulares em outras políticas, para ter o privilégio

\footnotetext{
${ }^{24}$ Disponível em:

http://www.camara.gov.br/proposicoesWeb/prop_mostrarintegra;jsessionid=568EDE4E02FF26F15A3EE3ADEC70 E235.node1 codteor $=965008 \&$ filename $=P L+3215 / 2012$

${ }^{25}$ Disponível em: http://www.camara.gov.br/proposicoesWeb/fichadetramitacao?idProposicao=554184

${ }^{26}$ Disponível em: http://portal.mec.gov.br/index.php?option=com_content\&view=article\&id=17631\&Itemid=866

${ }^{27}$ Disponível em: http://portal.mec.gov.br/index.php?option=com_content\&view=article\&id=17810\&Itemid=866

${ }^{28}$ Disponível em: http://www.portal.mec.gov.br
} 
de virar uma política específica, ganhando a partir disso um espaço estratégico na estrutura dos governos e, agora, consolida-se nos orçamentos públicos, especialmente pelo Programa Escolas Sustentáveis, que se encontra em implantação.

\section{Intersecções entre educação ambiental e audiodescrição}

O documento final da Rio+20, "O Futuro que Queremos"29, destacou cinco pontos que fazem referência às pessoas com deficiência, trazendo, portanto, esta importante contribuição na afirmação da acessibilidade como um direito humano das pessoas com deficiência e um elemento básico das políticas e iniciativas de sustentabilidade no âmbito das Nações Unidas.

Na sequência destas reflexões, em setembro de 2013, a sessão plenária da Reunião de Alto Nível sobre Desenvolvimento e Deficiência da ONU aprovou um documento que estabeleceu a acessibilidade às pessoas com deficiência como aspecto intrínseco ao desenvolvimento sustentável. A deliberação significou um êxito das posições defendidas pelo Brasil durante a realização do evento preparatório intitulado Consulta das Américas, ocorrido em Salvador (BA), com a participação de 20 países.

Decorrente dos desafios propostos na Rio+20, foi concluído o debate sobre os Objetivos do Desenvolvimento Sustentável (ODS) e a Agenda Pós-2015 $5^{30}$, que será sequência dos ODM. Os 193 Estados-Membros ONU, após a conclusão de um processo de negociação que contou com a participação da sociedade civil, apresentou os 17 novos objetivos que visam acabar com a pobreza, promover a prosperidade e o bem-estar das pessoas, protegendo o meio ambiente até 2030.

As pessoas com deficiência, que haviam ficado de fora dos ODM, são citadas várias vezes no documento atual, em temas como educação, trabalho, igualdade, cidades acessíveis, estatísticas, empoderamento entre outros. A Nova Agenda Transformando nosso mundo - A Agenda 2030 para o Desenvolvimento Sustentável, destaca, logo no início que engloba todos os direitos humanos (The 2030 Agenda for Global Action, 2015)

No ponto vista da produção de conhecimentos sobre o tema, a articulação da educação ambiental com a inclusão, conforme alguns registros históricos levantados, um dos primeiros eventos em que ocorreu esforço para este diálogo, podemos destacar o VI Fórum Iberoamericano de Educação Ambiental, realizado em Joinville, Santa Catarina, em 2006, que teve, de forma pioneira, um debate temático sobre educação ambiental e sua relação com a educação

\footnotetext{
${ }^{29}$ Disponível em http://www.rio20.gov.br/documentos/documentos-da-conferencia/o-futuro-que-queremos/

${ }^{30}$ Desde 2013, seguindo mandato da Conferência Rio+20, as Nações Unidas vêm discutindo um conjunto de Objetivos de Desenvolvimento Sustentável (ODS), que deverão orientar as políticas nacionais e as atividades de cooperação internacional nos próximos quinze anos, sucedendo os Objetivos de Desenvolvimento do Milênio (ODM).
} 
especial. Nos anais do evento, o relatório final do Grupo de Trabalho que tratou desta questão, trouxe como principal deliberação e proposta de encaminhamentos futuros "Inserir o tema Educação Especial, envolvendo as pessoas com deficiência nas políticas públicas e programas de Educação Ambiental" (V IBERO, 2006).

Durante o VI Fórum Brasileiro de Educação Ambiental, ocorrido em julho de 2009 na cidade do Rio de Janeiro, novamente ocorre este debate em uma de suas jornadas temáticas, intitulada "Educação Ambiental e Diálogos com a Diversidade" que influenciou o documento final do Fórum, conhecido como a "Carta da Praia Vermelha", que destacou a necessidade do diálogo da educação ambiental com a diversidade humana (FORUM REBEA, 2010).

No IX Fórum Brasileiro de Educação Ambiental, realizado em setembro de 2017 em Balneário Camboriú, Santa Catarina, a programação reuniu esforços para que ocorre-se um diálogo entre sustentabilidade e acessibilidade. Além de uma mesa redonda tratando sobre "SUSTENTABILIDADE E ACESSIBILIDADE NA PERSPECTIVA DOS DIREITOS HUMANOS" e uma Jornada Temática abordando "DIÁLOGOS DA POLÍTICA DE EA COM A INCLUSÃO, ACESSIBILIDADE E A DIVERSIDADE DAS CULTURAS DE POVOS E COMUNIDADES TRADICIONAIS", o evento contou de forma inédita, com uma Comissão de Acessibilidade e Direitos Humanos ${ }^{31}$.

Conforme os elementos apresentados, observamos que o campo das discussões políticas e acadêmicas sobre educação ambiental, sustentabilidade e pessoas com deficiência tem se mostrado proveitoso nos últimos anos. Longe de realizar um histórico detalhado, procuramos apresentar alguns pontos os quais julgamos centrais para nos ajudar a fazer conexões entre estas questões.

\section{Análise dos projetos de Educação ambiental}

Se por um lado as políticas de educação ambiental se consolidam institucionalmente, o mesmo ocorre com as políticas de inclusão na qual insere-se a audiodescrição, conforme já abordado sinteticamente. Porém, poucos foram os momentos de convergência destas questões seja em âmbito acadêmico ou em programas governamentais. Assim, podemos analisar que ao longo das últimas décadas, é possível observar uma certa negligência das políticas ambientais na relação com a acessibilidade e os direitos da pessoa com deficiência.

Há algumas evidências que nos ajudam a compreender este processo. Analisaremos aqui, o PRONEA e seus desdobramentos. Iniciativas importantes como o Circuito Tela Verde, o

\footnotetext{
${ }^{31}$ Disponível em: http://ixfbea-ivecea.unifebe.edu.br/wiew//programming/programcao-geral.pdf
} 
Projeto Sala Verde e o Programa Escola Sustentáveis não se propuseram a estimular uma educação ambiental democrática em sua concepção mais ampla, mas distanciando-se do Tratado de Educação Ambiental para Sociedades Sustentáveis e Responsabilidade Global, documento referência, que traz já como um dos seus princípios iniciais que é um direito de todas as pessoas (BRASIL, 2011).

Apresentamos abaixo, um quadro que apresenta os principais programas oficiais ${ }^{32}$ de educação ambiental brasileira e suas versões atuais e como se comporta a acessibilidade para as pessoas com deficiência em sua concepção metodológica, pedagógica e política.

\section{Quadro 3 - Programas de Educação Ambiental e a relação com a pessoa com deficiência}

\begin{tabular}{|c|c|}
\hline Programa & Propostas relacionadas a Acessibilidade \\
\hline PRONEA (2005) & $\begin{array}{l}\text { Promover a inclusão digital para dinamizar o acesso a informações sobre a temática } \\
\text { ambiental, garantindo inclusive a acessibilidade de portadores de necessidades } \\
\text { especiais. } \\
\text { Criação de um programa de formação em educação ambiental voltado aos } \\
\text { profissionais da educação especial, abordando a importância da inclusão dos } \\
\text { portadores de necessidades especiais na capacitação dos educadores ambientais em } \\
\text { geral. } \\
\text { Capacitar para desenvolver o meio ambiente, especialmente recursos hídricos, como } \\
\text { tema transversal na educação básica e no ensino superior, } \\
\text { assim como na alfabetização de adultos portadores de necessidades }\end{array}$ \\
\hline & especiais. \\
\hline Projeto Sala Verde $(2004)^{33}$ & $\begin{array}{l}\text { Igualdade de condições: entre os diferentes públicos com os quais se trabalha; entre } \\
\text { os membros da equipe técnica; entre parceiros do CEA. Deve ser compreendida em } \\
\text { diversas dimensões: igualdade de condições de participação, de tomada de decisão, } \\
\text { de avaliação, etc; }\end{array}$ \\
\hline $\begin{array}{l}\text { Programa } \\
\text { Sustentáveis }\end{array}$ & $\begin{array}{l}\text { Espaço físico: utilização de materiais construtivos mais adaptados às condições } \\
\text { locais e de um desenho arquitetônico que permita a criação de edificações dotadas de } \\
\text { conforto térmico e acústico, que garantam acessibilidade, gestão eficiente da água e } \\
\text { da energia, saneamento e destinação adequada de resíduos. Esses locais possuem } \\
\text { áreas propícias à convivência da comunidade escolar, estimulam a segurança } \\
\text { alimentar e nutricional, favorecem a mobilidade sustentável e respeitam o patrimônio } \\
\text { cultural e os ecossistemas locais. }\end{array}$ \\
\hline $\begin{array}{l}\text { Circuíto Tela Verde } \\
(2015)^{34}\end{array}$ & $\begin{array}{l}\text { Os critérios de classificação dos filmes incluem: ... apresentar legenda ou outros } \\
\text { recursos que contribuam para a inclusão de públicos específicos. }{ }^{25}\end{array}$ \\
\hline
\end{tabular}

O que é possível observar nos principais programas e iniciativas no âmbito público, é justamente a ausência da inserção do conceito de igualdade de oportunidades. O PRONEA no 3 ,

\footnotetext{
${ }^{32}$ Programas do Governo Federal, vinculados ao OG, previstos nas estruturas do MMA e MEC.

${ }^{33}$ Disponível em http://www.mma.gov.br/educacao-ambiental/educomunicacao/salas-verdes\#oprojeto

${ }^{34}$ Disponível em http://www.mma.gov.br/educacao-ambiental/educomunicacao/circuito-tela-verde
} 
elaborado em 2005 apresenta algumas propostas pontuais.

O Projeto Sala Verde, de 2004, não apresentam nenhum desafio com relação a inclusão. Ambos são anteriores a Convenção da ONU, apesar da Constituição Federal e as Leis da Acessibilidade já garantirem estes direitos. O Circuito Tela Verde e o Programa Escolas Sustentáveis, mesmo sendo mais atuais, mantem os mesmos problemas dos programas anteriores.

O que é comum em todos eles - a ausência de uma ideia de acessibilidade baseada na igualdade de oportunidades e na eliminação de barreiras. A audiodescrição é ausente em todos, inclusive no Circuito Tela Verde que exclusivamente trata da exibição de filmes ambientais. Há assim, explícito a partir da observação destas ações oficiais, a dificuldade de garantir a participação das pessoas com deficiência no debate ambiental, especialmente, no que se relaciona a educação.

\section{Considerações finais}

Este trabalho desde o início, teve como preocupação tentar mostrar como as políticas públicas são construídas e internalizadas socialmente. Ao centrar foco para estes processos de construção, tendo como pano de fundo, inicialmente, os marcos legais em sua perspectiva histórica, percebe-se que dependendo dos atores envolvidos, há maiores ou menores distanciamentos entre as diferentes iniciativas.

Observando a construção social e política da educação ambiental e da audiodescrição, é possível determinar a necessidade de diálogo entre ambas em um contexto pedagógico. " $\mathrm{O}$ processo de conhecer faz parte da natureza mesma da educação de que a prática chamada educação popular não pode fazer exceção" (FREIRE, 2002, p. 132). A inclusão social e a acessibilidade possuem, então, pontos convergentes. A acessibilidade pode ser considerada como uma condição para que ocorra a superação de barreiras impeditivas do exercício da cidadania plena na sociedade pelas pessoas com deficiência. Conforme Borges:

pensar em sociedades sustentáveis, necessariamente implica em garantir uma nova discussão sobre acessibilidade, direitos humanos e cidadania. E a conferência nos estimulou a refletir sobre este legado, mesmo com todas as suas contradições (2013, p. 87)

Assim, a audiodescrição pode inserir-se como mais uma ferramenta pedagógica na direção da aproximação da educação ambiental com a inclusão da pessoa com deficiência. É fundamental que em todas as políticas e iniciativas de educação ambiental, formais ou informais, tenham como um de seus princípios e valores a igualdade de oportunidades como elemento 
central dos currículos, da gestão e dos espaços educativos, buscando assim a garantia de que as pessoas com deficiência e as demais pessoas tenham o mesmo tratamento no acesso a seus produtos e serviços, como estabelece o Tratado de Educação Ambiental para Sociedades Sustentáveis e Responsabilidade Global, quando diz que a educação ambiental "deve estimular a solidariedade, a igualdade e o respeito aos direitos humanos, valendo-se de estratégias democráticas e da interação entre as culturas."

O que fica de certa forma claro, é que sempre há uma disputa que é atravessada por questões teóricas e conceituais. Educação ambiental e audiodescrição no atual momento em que encontram, onde os conceitos e ideias de sustentabilidade e acessibilidade se afirmam na sociedade, nos apresentam uma possibilidade interessante de construir ações transversais, cujas dimensões são cada vez mais exigidas nas políticas públicas de educação. Ressaltamos o que Borges nos aponta:

Acessibilizar o ambiental significa fazer uma discussão ampla sobre como as mudanças no ambiente afetam a vida das pessoas com deficiência e também, quais as políticas públicas ambientais que efetivamente são acessíveis e inclusivas, de forma a garantir a participação e o protagonismo destas pessoas no cenário de discussão da sustentabilidade em igualdade de oportunidades com as demais pessoas $(2014$, p. 147$)$.

A construção teórica e política da audiodescrição são elementos-chave para que possamos entender quais seriam os próximos passos de sua internalização nas práticas de educação ambiental. O que propomos são alguns elementos ao debate, sem nenhuma intenção de que os mesmos sejam conclusivos, mas que ao menos instiguem educadores ambientais, pessoas com deficiência, audiodescritores a pensarem neste cardápio inicial de possibilidades as quais podem ser compartilhadas em diferentes espaços sociais.

\section{Referências}

BORGES, J.A.S. Sustentabilidade \& Acessibilidade: Educação Ambiental, Inclusão e direitos da pessoa com deficiência-práticas, aproximações teóricas, caminhos e perspectivas!. OAB Editora, 2014.

Inclusão e Acessibilidade: Contribuição ao Programa Nacional Escolas Sustentáveis. AmbientalMente sustentable: Revista científica galego-lusófona de educación ambiental, n. 15, p. 83-92, 2013.

.Educação ambiental na perspectiva da educação inclusiva. Olhar de Professor, v. 14, n. 2, p. 285-292, 2011.

BRASIL. Constituição Federal de 1988. Disponível em: www.planalto.gov.br/ccivil_03/constituicao/constitui\%C3\%A7ao.htm. Acesso em: 15 abr. 2016. . Ministério da Educação e Cultura. Lei 9.394, de 20 de dezembro de 1996. 
Estabelece as Diretrizes e Bases da Educação Nacional. 1996. Disponível em: http://portal.mec.gov.br/seed/arquivos/pdf/tvescola/leis/lein9394.pdf. Acesso em: 15 abr. 2016.

Implantação da educação ambiental no Brasil. Brasília: Coordenação de Educação Ambiental do Ministério da Educação e do Desporto. Texto: Silvia Czapski 1998.

Lei no 9.795 de 27 de abril de 1999. Institui a Política Nacional de Educação Ambiental. Brasília, 1999.

Decreto $n^{0} 3.298 / 99$, de 31 de dezembro de 1999. Regulamenta a Lei Federal $\mathrm{n}^{\circ}$ 7.853 , de 24 de outubro de 1989. Dispõe sobre a Política Nacional para Integração da Pessoa Portadora de Deficiência, Consolida as Normas de Proteção, e dá outras providências. Brasília, 2009.

. Ministério das Comunicações. Lei 10.098 - de 19 de dezembro de 2000. Estabelece normas gerais e critérios básicos para a promoção da acessibilidade das pessoas portadoras de deficiência ou com mobilidade reduzida, e dá outras providências. Disponível em: www.planalto.gov.br/ccivil/LEIS/L10098.htm. Acesso em: 15 abr. 2016.

SEESP, 2001.

Diretrizes Nacionais para Educação Especial na Educação Básica. MEC

Ministério das Comunicações. Decreto Federal 5.296 - de 2 de dezembro de 2004b. Regulamenta as Leis nos 10.048, de 8 de novembro de 2000, que dá prioridade de atendimento às pessoas que especifica, e 10.098, de 19 de dezembro de 2000, que estabelece normas gerais e critérios básicos para a promoção da acessibilidade das pessoas portadoras de deficiência ou com mobilidade reduzida, e dá outras providências. Disponível em www.planalto.gov.br/ccivil_03/_ato2004-2006/2004/decreto/d5296.htm. Acesso em: 15 abr. 2016.

Convenção sobre os Direitos das Pessoas com Deficiência: Protocolo facultativo à Convenção sobre os Direitos das Pessoas com Deficiência. Tradução Oficial/Brasil, Brasília: Presidência da República Secretaria Especial dos Direitos Humanos Coordenadoria Nacional para Integração da Pessoa Portadora de Deficiência, setembro/2007. $48 \mathrm{p}$.

Ministério da Educação. Política Nacional de Educação Especial na perspectiva da Educação Inclusiva. Brasília: MEC, 2008.

Os diferentes Matizes da Educação Ambiental no Brasil. 1997-2007. - 2. Ed. Brasília/DF: Ministério do Meio Ambiente. Texto: Silvia Czapski. 2009. Sociedades Sustentáveis e Responsabilidade Global. 2011. Disponível em http://portal.mec.gov.br/secad/arquivos/pdf/educacaoambiental/tratado.pdf. Acesso em: 15 abr. 2016.

. Casa Civil. Plano Nacional de Educação. 2014. Disponível em www.planalto.gov.br/ccivil_03/_Ato2011-2014/2014/Lei/L13005.htm. Acesso em: 15 abr. 2016.

CARTA da Praia Vermelha. Fórum Rebea, 18 jun. 2010. Disponível em: <http://forumearebea.org/wp-content/uploads/CARTA-DA-PRAIA-VERMELHA1.pdf $>$. Acesso em: 15 abr. 2016.

FÓRUM IBERO-AMERICANO DE EDUCAÇÃO AMBIENTAL, 6. Joinvile, SC, 2006. 1 CD. 
FRANCO, E. P. C.; SILVA, MCCC. Audiodescrição: breve passeio histórico. Audiodescrição: transformando imagens em palavras. São Paulo: Secretaria dos Direitos da Pessoa com Deficiência do Estado de São Paulo, p. 19-36, 2010.

FREIRE, P. Pedagogia da esperança. Rio de Janeiro: Paz e Terra.

GALEANO, E. Os filhos dos dias. E. Nepomuceno, Trad.). Porto Alegre: L\&PM Editores (2012).

HENKIN, Louis. The rights of man today. [S.I.: s.n.] [19-].

JIMENEZ HURTADO, C.; RODRÍGUEZ, A.; SEIBEL, C. Un corpus del cine. Teora y practica de la audiodescriptión. Granada: Tragacanto, 2010.

MOTTA, L. M. V. M.; ROMEU FILHO, P. (org). Audiodescrição: transformando imagens em palavras. São Paulo: Secretaria dos Direitos da Pessoa com Deficiência do Estado de São Paulo, 2010.

Norma Brasileira ABNT NBR 15290:2005, que dispõe sobre Acessibilidade em Comunicação na Televisão.

SASSAKI, R. K. Terminologia sobre deficiência na era da inclusão. Mídia e deficiência. Brasília: Fundação Banco do Brasil, p. 160-165, 2003.

. Inclusão: acessibilidade no lazer, trabalho e educação. Revista Nacional de Reabilitação (Reação), São Paulo, Ano XII, mar./abr. 2009, p. 10-16.

SORRENTINO, M. et al. Educação ambiental como política pública. Educação e Pesquisa, São Paulo, v. 31, n. 2, p. 285-299, 2005. 